\title{
An Observational Study: Ambulatory Blood Pressure Monitoring after Percutaneous Transluminal Coronary Angioplasty
}

\author{
Gopi Krishna Kenchi ${ }^{1}$ Sunisha Gajula ${ }^{2}$ Malleshwar Rao Dangati ${ }^{1}$
}

\author{
${ }^{1}$ Department of Cardiology, Nizam's Institute of Medical Sciences, \\ Punjagutta, Hyderabad, Telangana, India \\ 2Department of Ophthalmology, PMRIMS, Hyderabad, Telangana, India
}

\begin{abstract}
Address for correspondence Gopi Krishna Kenchi, MD (DM), Department of Cardiology, Nizam's Institute of Medical Sciences, Punjagutta, Hyderabad 500082, Telangana, India (e-mail: drgopikrishna44@gmail.com).
\end{abstract}

Indian J Cardiovasc Dis Women-WINCARS 2018;3:17-22

\section{Abstract}

Keywords

- ambulatory blood pressure monitoring

- coronary artery disease

- percutaneous transluminal coronary angioplasty
Aim In recent studies, lack of fall in nocturnal blood pressure (BP) has been presented as an independent predictor of poor prognosis. The aim of this study is to investigate the prognostic value of various variables of BP by 24-hour ambulatory blood pressure $(\mathrm{ABP})$ measurement and sex-related differences after percutaneous transluminal coronary angioplasty (PTCA).

Methods This study included 100 patients who underwent PTCA in the authors' institute from June 2017 to January 2018. They were monitored by 24-hour ABP for 1 day in the hospital.

Results One hundred patients were recruited in this study with mean age of 61.64 years, with female-to-male ratio of 0.27:1. All demographic, clinical, and laboratory parameters including the ABP parameters were comparable between females and males, except smoking and alcoholism that were more frequent in males.

Out of 100 patients, 41 had nocturnal dipping in BP and 59 did not have nocturnal dipping. In this study, the variables among nondippers, 16 (27.1\%) were females, 43 (72.8\%) were males, 45 (63.3\%) had diabetes mellitus (DM), 46 (75.4\%) had hypertension (HTN), mean systolic blood pressure (SBP) was $141.7 \pm 13.9 \mathrm{~mm} \mathrm{Hg}$, mean diastolic blood pressure (DBP) was $86.34 \pm 5.64 \mathrm{~mm} \mathrm{Hg}$, mean pulse pressure (PP) was $55.39 \pm 9.25 \mathrm{~mm} \mathrm{Hg}$, and pulse-wave velocity $(P W V)$ was $6.69 \pm 2.22 \mathrm{~m} / \mathrm{s}$.

In females were more nondippers (27.1\%) than dippers (12.1\%), which was statistically significant $(p=0.05)$. Nondippers were more among hypertensive patients (77.9\% vs. 36.5\%; $p=0.00)$. Higher mean SBP $(p=0.001)$, higher mean BP $(p=0.032)$, and higher mean pulse pressure $(p=0.00)$ were observed in nondippers. However, age, ejection fraction (EF), presence of DM, coronary artery disease (CAD) severity, type of presentation, and PWV were not different in dipper versus nondippers.

Conclusion With comparable clinical, laboratory parameters along with BP parameters between females and males, immediate post-percutaneous coronary intervention $(\mathrm{PCl})$ patients, female $\mathrm{PCl}$ patients had more nondippers $(p=0.05)$. Overall nondippers had higher SBP, mean BP, and PP than dippers. Diabetes, severity of CAD, and type of presentation of CAD (as ACS or CSA) did not influence the nocturnal dipping quality of the BP.
License terms

()(1) $\Theta \circledast$ 


\section{Introduction}

In the past decade, there has been an explosive growth of ambulatory blood pressure (ABP) monitoring for clinical purposes and research. ${ }^{1,2}$ Several outcome studies have been published, particularly during the past few years. ${ }^{1-25}$ These studies were conducted in the general population ${ }^{19,20}$ or in hypertensive subjects, who were either untreated ${ }^{3-14,16}$ or treated ${ }^{15,17,18}$ at the time of ABP monitoring. The general result of these studies was that the difference in the cardiovascular disease (CVD) risk between categories generated by one session of $\mathrm{ABP}$ monitoring was greater than the difference in the risk between categories generated by one or a few standard office blood pressure (BP) measurements.

The aim of this study was to investigate the prognostic value of various variables of BP obtained by 24-hour ABP measurement and sex-related differences after percutaneous transluminal coronary angioplasty (PTCA).

\section{Methods}

This was a prospective, observational, and single-center study. This study was conducted in the department of cardiology at our institute. This study included 100 consecutive patients who underwent PTCA in our institute from June 2017 to January 2018 irrespective of presence or absence of hypertension (HTN). This study was approved by the institutional review board. An informed written consent was obtained from the participants before recruiting them in this study. Major exclusion criteria were patients having hemodynamic instability requiring intra-aortic balloon pump (IABP) or inotropic support or mechanical ventilation, insomnia, and arrhythmia that interfere with ABP monitoring devices. Baseline data regarding age, sex, and conventional coronary artery disease (CAD) risk factors (diabetes mellitus [DM], HTN, and smoking) were collected. Diagnosis and indication for percutaneous coronary intervention $(\mathrm{PCI})$ were recorded. All patients were subjected to undergo routine blood investigations, including complete blood counts, blood sugar, liver function tests (LFT), lipid profile, blood urea, serum creatinine, and serum electrolytes. Electrocardiogram (ECG) and transthoracic echocardiography were performed for all patients. They were monitored by ABP for 24 hours in the hospital.

Table 1 Demographics of study population

\begin{tabular}{|l|l|}
\hline Variable & Number \\
\hline Age $(y)$ & $61.64 \pm 8.50$ \\
\hline Females & $21(21 \%)$ \\
\hline Males & $79(79 \%)$ \\
\hline DM & $71(71 \%)$ \\
\hline HTN & $61(61 \%)$ \\
\hline Smoking & $31(31 \%)$ \\
\hline ACS & $59(59 \%)$ \\
\hline CSA & $41(41 \%)$ \\
\hline
\end{tabular}

Abbreviations: ACS, acute coronary syndrome; CSA, chronic stable angina; DM, diabetes mellitus; HTN, hypertension.

\section{Ambulatory Blood Pressure Monitoring}

The 24-hour ABP measurement was performed using a portable compact digital recorder (Tonoport V, GE Healthcare) and an analyzer using customized analytical software programmed to measure BPs at 15-minute intervals during day time from 07:00 until 23:00, and at 30-minute intervals during night time from 23:00 until 07:00. The patients were instructed to perform their routine daily activities, but to stay inactive during the measurements. Recordings were accepted if more than $80 \%$ of the raw data were valid. The inflatable cuff was always placed on the nondominant upper limb.

The analyzed variables included the following: mean SBP, mean DBP, mean PP, mean pulse-wave velocity (PWV), and presence or absence of dipping.

\section{Results}

The demographic details of the study were given in - Table 1 and - Fig. 1 .

Out of 100 patients, 21 (21\%) were females and 79 (79\%) were males ( $\mathbf{- F i g . 1}$ ). Mean age of study population is 61.64 \pm 8.50 years. Overall, $61(61 \%)$ patients had HTN, $71(71 \%)$ had DM, and 31 (31\%) had a history of smoking (-Fig. 2). The most common presentation in our study was acute coronary syndrome (ACS) (59\%) that comprises unstable angina, non-ST-elevation myocardial infarction (NSTEMI), and ST-elevation myocardial infarction (STEMI).

- Table 2 compares baseline characteristics based on sex. Both the groups were comparable regarding age, DM, HTN, number of stents, mean EF, and number of diseased vessels, except male patients who were more likely to have history of alcohol consumption and smoking. Mean age did not differ significantly between female and male patients (62.48 \pm 7.88 years vs. $61.4 \pm 8.7$ years, $p=0.59$ ) ( - Fig. 3 ). The mean EF among female patients was $56.3 \pm 10.31 \%$ and among male patients was $52.65 \pm 10.85 \%(p=0.15)$, which is not statistically significant $(p=0.15)$.

From the ABP monitoring different variables were noted. No significant differences in various parameters obtained from $A B P$ were noted between male and female patients.

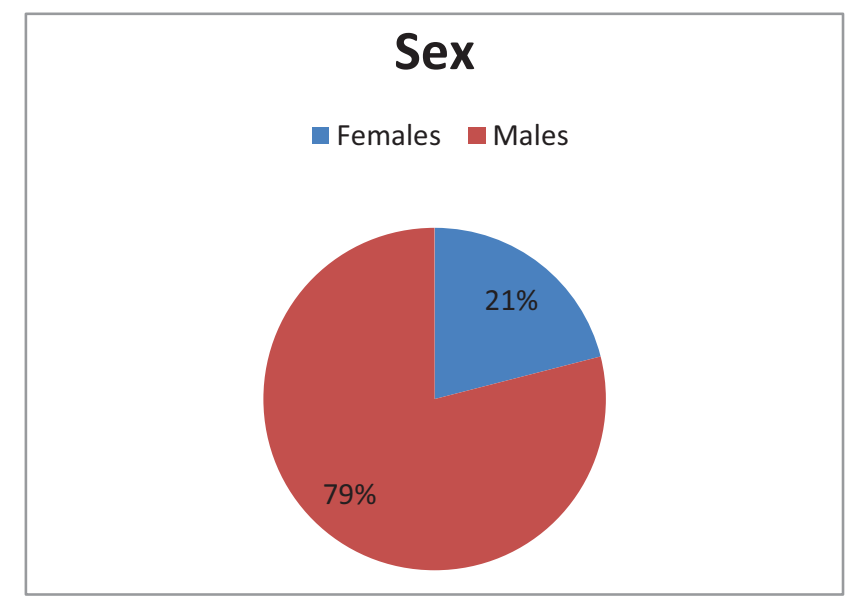

Fig. 1 Sex distribution of the study population. 
Table 2 Clinical, risk factors, and CAG data in both female and male patients

\begin{tabular}{|l|l|l|l|}
\hline Variable & Female (mean \pm SD) & Male (mean \pm SD) & $p$ Value \\
\hline Age $(y)$ & $62.48 \pm 7.88$ & $61.42 \pm 8.70$ & 0.59 \\
\hline Hypertension (\%) & $15(24.59 \%)$ & $46(75.40 \%)$ & 0.24 \\
\hline Diabetic mellitus (\%) & $16(22.53 \%)$ & $55(77.46 \%)$ & 0.53 \\
\hline Smoking (\%) & $1(4.7 \%)$ & $32(40.5 \%)$ & 0.00 \\
\hline Alcoholism (\%) & 0 & $33(42.3 \%)$ & 0.00 \\
\hline Stents (no. per patient) & $2.00 \pm 0.71$ & $1.77 \pm 0.60$ & 0.18 \\
\hline Ejection fraction (\%) & $56.33 \pm 10.31$ & $52.65 \pm 10.85$ & 0.15 \\
\hline CAG (single vs. multi) & $12(57.1 \%)$ & $52(65.8 \%)$ & 0.47 \\
\hline
\end{tabular}

Abbreviations: CAG, coronary angiography; SD, standard deviation.

Table 3 Different ABP parameters in both female and male patients

\begin{tabular}{|l|l|l|l|}
\hline Variable & Female (mean \pm SD) & Male (mean \pm SD) & $p$ Value \\
\hline Mean systolic blood pressure $(\mathrm{mm} \mathrm{Hg})$ & $140.76 \pm 17.20$ & $135.77 \pm 16.66$ & 0.24 \\
\hline Mean diastolic blood pressure $(\mathrm{mm} \mathrm{Hg})$ & $85.33 \pm 6.04$ & $85.09 \pm 11.36$ & 0.89 \\
\hline Average mean blood pressure $(\mathrm{mm} \mathrm{Hg})$ & $104.19 \pm 9.54$ & $102.33 \pm 12.72$ & 0.46 \\
\hline Mean pulse pressure $(\mathrm{mm} \mathrm{Hg})$ & $55.43 \pm 11.97$ & $50.68 \pm 8.69$ & 0.10 \\
\hline Mean heart rate (beats/min) & $71.95 \pm 19.12$ & $72.66 \pm 17.22$ & 0.87 \\
\hline Pulse-wave velocity $(\mathrm{m} / \mathrm{s})$ & $7.06 \pm 2.18$ & $164.54 \pm 6.40$ & 0.54 \\
\hline Maximum systolic blood pressure $(\mathrm{mm} \mathrm{Hg})$ & $166.95 \pm 8.16$ & $112.81 \pm 6.97$ & 0.22 \\
\hline Maximum diastolic blood pressure $(\mathrm{mm} \mathrm{Hg})$ & $110.95 \pm 5.58$ & $109.84 \pm 9.28$ & 0.20 \\
\hline Minimum systolic blood pressure $(\mathrm{mm} \mathrm{Hg})$ & $112.86 \pm 8.82$ & $59.93 \pm 7.05$ & 0.17 \\
\hline Minimum diastolic blood pressure $(\mathrm{mm} \mathrm{Hg})$ & $61.38 \pm 9.01$ & 0.50 \\
\hline
\end{tabular}

Abbreviations: ABP, ambulatory blood pressure.

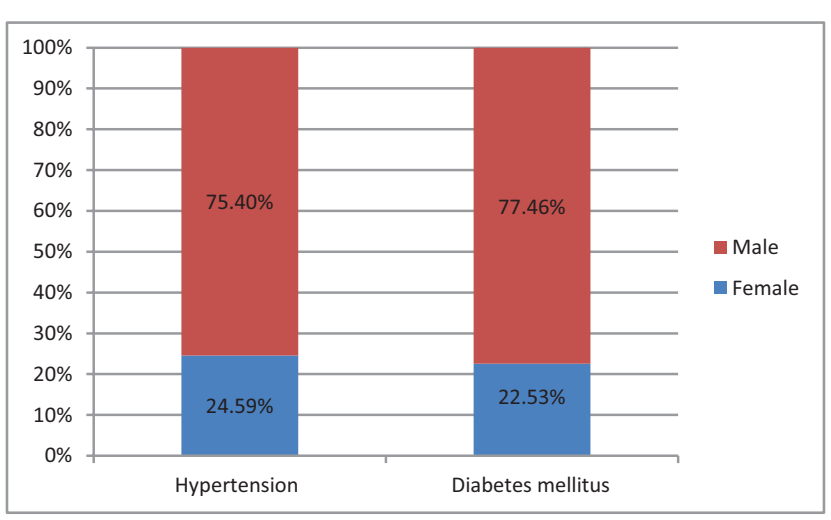

Fig. 2 Sex distribution among diabetes mellitus and hypertension.

Mean BP of female and male patients was identical (104.19 \pm 9.54 vs $102.33 \pm 12.72 \mathrm{~mm} \mathrm{Hg}, p=0.46$ ). The average PWV among female patients was $7.06 \pm 2.18 \mathrm{~m} / \mathrm{s}$, and among male patients it was $6.72 \pm 2.52 \mathrm{~m} / \mathrm{s}$, which was not statistically significant $(p=0.54)$. Statistically significant sex difference was not there even in mean systolic blood pressure (SBP), mean diastolic blood pressure (DBP), and pulse pressure (PP) (- Table 3). The mean heart rate (HR) among female and male patients was similar ( $71.95 \pm 19.12$ vs. $72.66 \pm 17.22$ beats/ min, $p=0.87)(-$ Table 2).

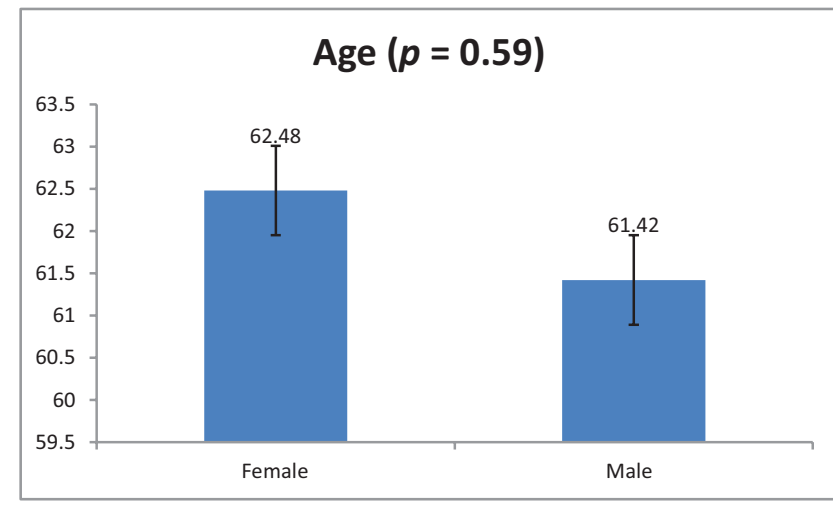

Fig. 3 Age comparison between males and females.

Among 100 patients, $41(41 \%)$ patients had nocturnal dipping and 59 (59\%) did not have nocturnal dipping. When comparing the different demographic, clinical, and laboratory parameters between nocturnal dippers and blunted dippers, female patients were more likely to have nondipping $(p=0.05)$. Patients with prior history of HTN had nondipping nocturnal BP compared with prior normotensive patients ( $77.9 \%$ vs. $36.5 \%, p=0.001$ ). Nondippers had higher 24 hours mean SBP $(p=0.001)$, 24-hours mean BP $(p=0.032)$, and 
24-hours mean PP compared with dippers, which was statistically significant $(p=0.00)$ ( - Table $4,-$ Fig. 4). However, there was no significant difference in 24-hour mean HR and 24-hours mean PWV between dippers and nondippers. Mean age, mean EF, presence of DM, CAD severity, and type of presentation were not different in dipper versus nondippers (-Fig. 5).

\section{Discussion}

Arterial BP exhibits a diurnal rhythm that is higher at daytime than at nighttime. ${ }^{26-28}$ A nocturnal fall in BP of less than $10 \%$ of the daytime value has been termed as "nondippers." ${ }^{29}$ Continuous 24-hour ABP monitoring has been used to show the diurnal rhythm of arterial BP. The mechanisms responsible for abnormal diurnal variation in BP remain unclear, but it may be associated with an autonomic balance deterioration..$^{30}$ Erdem et al reported a possible cardiac autonomic dysfunction in prehypertensive, nondipper patients. ${ }^{31}$ Verdecchia et al demonstrated that lack of nocturnal decline in BP in patients with essential HTN was a good predictor of cardiovascular prognosis. ${ }^{5}$ Furthermore, nondipper pattern is a predictor of target organ damage, including stroke, renal failure, and adverse cardiovascular events. ${ }^{32-34}$ Kang et al reported that CAD patients often had lack of nocturnal BP fall, which might increase the future coronary events risk, including ACS. ${ }^{35}$ Zain-El et al reported that in elderly patients with isolated systolic HTN nondipping morning BP was an

Table 4 Comparison of different parameters in dippers versus nondippers

\begin{tabular}{|c|c|c|c|c|}
\hline \multicolumn{2}{|l|}{ Variables } & Nondippers (mean \pm SD) & Dippers (mean \pm SD) & $p$ Value \\
\hline \multicolumn{2}{|l|}{ Age } & $62.78 \pm 7.93$ & $60.00 \pm 9.13$ & 0.118 \\
\hline \multicolumn{2}{|l|}{$\mathrm{EF}$} & $53.2 \pm 10.2$ & $53.8 \pm 11.7$ & 0.788 \\
\hline \multicolumn{2}{|l|}{ Females } & $16(27.1 \%)$ & $5(12.1 \%)$ & 0.05 \\
\hline \multicolumn{2}{|l|}{ Males } & $43(72.8 \%)$ & $36(87.8 \%)$ & 0.08 \\
\hline \multicolumn{2}{|l|}{ DM } & $45(76.27 \%)$ & $26(63.4 \%)$ & 0.16 \\
\hline \multicolumn{2}{|l|}{ HTN } & $46(77.9 \%)$ & $15(36.5 \%)$ & 0.001 \\
\hline \multirow[t]{2}{*}{ CAD } & SVD & $29(70.7 \%)$ & $35(59.3 \%)$ & 0.23 \\
\hline & DVD & $12(29.2 \%)$ & $24(40.6 \%)$ & 0.23 \\
\hline \multirow[t]{2}{*}{ Presentation } & CSA & $15(36.5 \%)$ & $26(44.06 \%)$ & 0.45 \\
\hline & ACS & $26(63.4 \%)$ & $33(55.9 \%)$ & 0.45 \\
\hline \multirow[t]{3}{*}{ Stents } & 1 & $15(25.4 \%)$ & $16(39.02 \%)$ & 0.15 \\
\hline & 2 & $34(57.6 \%)$ & $23(56.09 \%)$ & 0.87 \\
\hline & 3 & $10(16.9 \%)$ & $2(4.8 \%)$ & 0.042 \\
\hline \multicolumn{2}{|l|}{ Mean SBP } & $141.7 \pm 13.9$ & $129.8 \pm 18.3$ & 0.001 \\
\hline \multicolumn{2}{|l|}{ Mean DBP } & $86.34 \pm 5.64$ & $83.4 \pm 14.8$ & 0.234 \\
\hline \multicolumn{2}{|l|}{ Mean MBP } & $105.12 \pm 8.20$ & $99.3 \pm 15.6$ & 0.032 \\
\hline \multicolumn{2}{|l|}{ Mean PP } & $55.39 \pm 9.25$ & $46.34 \pm 7.42$ & 0.000 \\
\hline \multicolumn{2}{|l|}{ Mean HR } & $73.0 \pm 16.9$ & $71.8 \pm 18.6$ & 0.735 \\
\hline \multicolumn{2}{|l|}{ PWV } & $6.69 \pm 2.22$ & $6.94 \pm 2.76$ & 0.637 \\
\hline
\end{tabular}

Abbreviations: ACS, acute coronary syndrome; CAD, coronary artery disease; CSA, chronic stable angina; DBP, diastolic blood pressure; DM, diabetes mellitus; DVD, double-vessel disease; EF, ejection fraction; HR, heart rate; HTN, hypertension; MBP, mean blood pressure; PP, pulse pressure; PWV, pulse-wave velocity; SBP, systolic blood pressure; SVD, single-vessel disease.

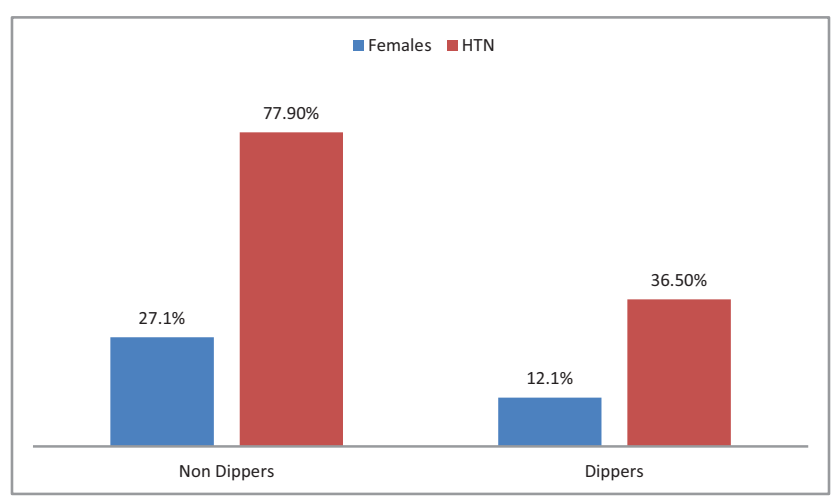

Fig. 4 Statistically significant variables $(p<0.05)$ in dippers and nondippers in females.

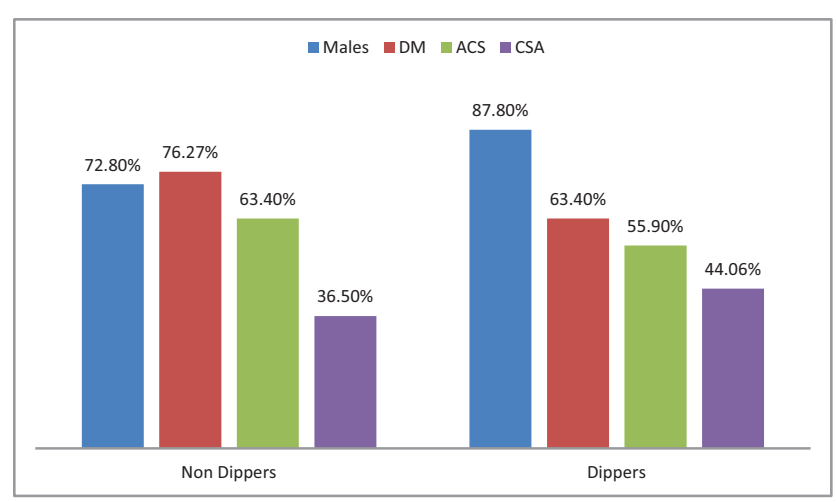

Fig. 5 Statistically insignificant variables $(p>0.05)$ in dippers and nondippers in males. 
independent predictor of hypertensive target organ damage. ${ }^{36}$ Cha et al reported that masked and sustained HTN and nondipping or reverse dipping pattern were more common in patients with severe renal failure and proteinuria. ${ }^{37}$ Karakas et al demonstrated the nondipping BP pattern relation with impaired left ventricular dyssynchrony in dipper and nondipper hypertensives. ${ }^{38}$

In our study, we observed that women had blunted nocturnal dipping ( $p=0.05)$ when compared with men $(p=0.08)$. This finding is consistent with previous study reports by Sherwood et $\mathrm{al}^{39}$ which concluded that women with CAD may be exposed to a higher nocturnal BP, which could put them at higher risk for further target organ damage and adverse clinical outcomes. They also noted that ambulatory PP was elevated during both the daytime and nighttime in women with CAD. They also showed that CAD and advancing age were associated with blunted nocturnal BP dipping in women.In the PIUMA (Progetto Ipertensione Umbria Monitoraggio Ambulatoriale) study, hypertensive women with nondipping pattern at the baseline evaluation had a higher cardiovascular morbidity rate during follow-up than dippers, and this difference remained significant even after control for traditional risk factors. A nonsignificant trend in the same direction was found in men. ${ }^{5}$

A recent study by Cicek et al ${ }^{40}$ observed that 56 (66.66\%) patients had nondipper pattern and 28 (33.33\%) had dipper pattern. They observed a significant difference in CF-PWV (nondipper vs. dipper; $8.91 \pm 2.53$ vs. $7.66 \pm 1.08 \mathrm{~m} / \mathrm{s}, p=0.002$ ), female sex ( $55 \%$ vs. $32 \%, p=0.045)$, and nocturnal BP measurements (for mean BP; $106 \pm 11$ vs. $92 \pm 8 \mathrm{~mm} \mathrm{Hg}, p<0.001$ ). By multiple logistic regression analysis, they revealed female sex $(p=0.021)$, nocturnal mean BP $(p<0.001)$, and CF-PWV $(p=0.004)$ as the independent predictors of nondipper hypertensive pattern. Nondipper pattern, mainly related to increased PWV and impaired modulation of vascular smooth muscle tone during the night, may justify an increased cardiovascular risk in these patients.

This study results were consistent with those of our study in terms of female sex (nondippers vs. dippers; $27 \%$ vs. $12 \%$, $p=0.05)$ and high mean BP $(105.12 \pm 8.20$ vs. $99.3 \pm 15.6 \mathrm{~mm}$ $\mathrm{Hg}, p=0.032$ ). However, in contrast PWV was not statistically significant between the two groups $(6.69 \pm 2.22$ vs. $6.94 \pm 2.76$, $p=0.637$ ).

In our study, we found the statistically higher 24-hour PP in nondippers than dippers $(p=0.00)$. This finding was consistent with previous study reports by Verdecchia et $a l,{ }^{10}$ which concluded that ambulatory PP was a potent independent predictor of total cardiovascular risk in initially untreated essential hypertensive white patients. Ambulatory PP was a more accurate marker than office PP of increased arterial stiffness or already diseased arteries. ${ }^{41}$ In CAD patients there was an association between a higher PP and cardiac events. ${ }^{42}$ The elevated PP was a result of increased conduit vessel stiffness. Furthermore, it was likely that the increased load associated with conduit vessel stiffening contributed to a reduction in stroke volume in the patients with increased PP. The stiffness of Conduit vessel increased the amplitude of PP produced by a given flow wave, resulting in higher systolic and lower diastolic pressures for any given mean pressure. In stiffened conduit vessels PWV was increased, and this shortened the time required for the forward pressure wave to travel down the aorta and peripheral conduits to the various reflecting sites and back to the heart. The resulting movement of the reflected wave into systole from diastole has no effect on mean arterial pressure (MAP). However, the premature reflected wave further increases the systolic pressure-time integral and decreases the diastolic pressure-time integral, thereby increasing systolic load while decreasing coronary perfusion pressure.

\section{Conclusion}

With comparable clinical, laboratory parameters along with BP parameters between females and males, immediate postPCI patients and female PCI patients had more nondippers $(\mathrm{p}=0.05)$. Overall nondippers had higher SBP, mean BP, and PP than dippers. Diabetes, severity of CAD, and type of presentation of CAD (as ACS or CSA) did not influence the nocturnal dipping quality of the BP.

\section{Limitations of the Study}

This study provided no information regarding long-term clinical outcomes. It was a nonrandomized study from a single center.

\section{Conflict of Interest}

None.

\section{References}

1 Pickering T; American Society of Hypertension Ad Hoc Panel. Recommendations for the use of home (self) and ambulatory blood pressure monitoring. Am J Hypertens 1996;9(1):1-11

2 Mallion J-M, Baguet J-P, Siché J-P, Tremel F, De Gaudemaris R. Clinical value of ambulatory blood pressure monitoring. J Hypertens 1999;17(5):585-595

3 Perloff D, Sokolow M, Cowan R. The prognostic value of ambulatory blood pressures. JAMA 1983;249(20):2792-2798

4 Perloff D, Sokolow M, Cowan RM, Juster RP. Prognostic value of ambulatory blood pressure measurements: further analyses. J Hypertens Suppl 1989;7(3):S3-S10

5 Verdecchia P, Porcellati C, Schillaci G, et al. Ambulatory blood pressure. An independent predictor of prognosis in essential hypertension. Hypertension 1994;24(6):793-801

6 Verdecchia P, Schillaci G, Borgioni C, Ciucci A, Gattobigio R, Porcellati C. Nocturnal pressure is the true pressure. Blood Press Monit 1996;1(Suppl 2):S81-S85

7 Verdecchia P, Borgioni C, Ciucci A, et al. Prognostic significance of blood pressure variability in essential hypertension. Blood Press Monit 1996;1(1):3-11

8 Verdecchia P, Schillaci G, Borgioni C, Ciucci A, Porcellati C. Prognostic significance of the white coat effect. Hypertension 1997;29(6):1218-1224

9 Verdecchia P, Schillaci G, Borgioni C, et al. Adverse prognostic value of a blunted circadian rhythm of heart rate in essential hypertension. J Hypertens 1998;16(9):1335-1343

10 Verdecchia P, Schillaci G, Borgioni C, Ciucci A, Pede S, Porcellati C. Ambulatory pulse pressure: a potent predictor of total cardiovascular risk in hypertension. Hypertension 1998;32(6):983-988 
11 Verdecchia P, Schillaci G, Borgioni C, et al. Altered circadian blood pressure profile and prognosis. Blood Press Monit 1997;2(6):347-352

12 Verdecchia P, Schillaci G, Gatteschi C, et al. Blunted nocturnal fall in blood pressure in hypertensive women with future cardiovascular morbid events. Circulation 1993;88(3):986-992

13 Pickering TG, James GD. Ambulatory blood pressure and prognosis. J Hypertens Suppl 1994;12(8):S29-S33

14 Khattar RS, Senior R, Lahiri A. Cardiovascular outcome in white-coat versus sustained mild hypertension: a 10-year follow-up study. Circulation 1998;98(18):1892-1897

15 Zweiker R, Eber B, Schumacher M, Toplak H, Klein W. "Nondipping" related to cardiovascular events in essential hypertensive patients. Acta Med Austriaca 1994;21(3):86-89

16 Staessen JA, Thijs L, Fagard R, et al; Systolic Hypertension in Europe Trial Investigators. Predicting cardiovascular risk using conventional vs ambulatory blood pressure in older patients with systolic hypertension. JAMA 1999;282(6):539-546

17 Yamamoto Y, Akiguchi I, Oiwa K, Hayashi M, Kimura J. Adverse effect of nighttime blood pressure on the outcome of lacunar infarct patients. Stroke 1998;29(3):570-576

18 Redon J, Campos C, Narciso ML, Rodicio JL, Pascual JM, Ruilope LM. Prognostic value of ambulatory blood pressure monitoring in refractory hypertension: a prospective study. Hypertension 1998;31(2):712-718

19 Imai Y, Ohkubo T, Tsuji I, et al. Prognostic value of ambulatory and home blood pressure measurements in comparison to screening blood pressure measurements: a pilot study in Ohasama. Blood Press Monit 1996;1(Suppl2):S51-S58

20 Ohkubo T, Imai Y, Tsuji I, et al. Prediction of mortality by ambulatory blood pressure monitoring versus screening blood pressure measurements: a pilot study in Ohasama. J Hypertens 1997;15(4):357-364

21 Mancia G, Verdecchia P. Clinical value of ambulatory blood pressure: evidence and limits. Circ Res 2015;116(6):1034-1045

22 Myers MG, Kaczorowski J, Dolovich L, Tu K, Paterson JM. Cardiovascular risk in hypertension in relation to achieved blood pressure using automated office blood pressure measurement. Hypertension 2016;68(4):866-872

23 Kumar A, Kalmath BC, Abraham G, et al. Role and relevance of blood pressure variability in hypertension related co-morbidities. J Assoc Physicians India 2017;65(12):83-92

24 Tocci G, Presta V, Figliuzzi I, et al. Prevalence and clinical outcomes of white-coat and masked hypertension: analysis of a large ambulatory blood pressure database. J Clin Hypertens (Greenwich) 2018;20(2):297-305

25 Cuspidi C, Facchetti R, Bombelli M, et al. Night-time heart rate nondipping: clinical and prognostic significance in the general population. J Hypertens 2018;36(6):1311-1317

26 Richardson DW, Honour AJ, Fenton GW, Stott FH, Pickering GW. Variation in arterial pressure throughout the day and night. Clin Sci 1964;26:445-460

27 Millar-Craig MW, Bishop CN, Raftery EB. Circadian variation of blood-pressure. Lancet 1978;1(8068):795-797
28 Campos LA, Bader M, Baltatu OC. Brain renin-angiotensin system in hypertension, cardiac hypertrophy, and heart failure. Front Physiol 2012;2:115

29 Verdecchia P, Schillaci G, Guerrieri M, et al. Circadian blood pressure changes and left ventricular hypertrophy in essential hypertension. Circulation 1990;81(2):528-536

30 Brotman DJ, Davidson MB, Boumitri M, Vidt DG. Impaired diurnal blood pressure variation and all-cause mortality. Am J Hypertens 2008;21(1):92-97

31 Erdem A, Uenishi M, Küçükdurmaz Z, et al. Cardiac autonomic function measured by heart rate variability and turbulence in pre-hypertensive subjects. Clin Exp Hypertens 2013;35(2):102-107

32 Ohkubo T, Imai Y, Tsuji I, et al. Relation between nocturnal decline in blood pressure and mortality. The Ohasama study. Am J Hypertens 1997;10(11):1201-1207

33 Lurbe E, Redon J, Kesani A, et al. Increase in nocturnal blood pressure and progression to microalbuminuria in type 1 diabetes. N Engl J Med 2002;347(11):797-805

34 Davidson MB, Hix JK, Vidt DG, Brotman DJ. Association of impaired diurnal blood pressure variation with a subsequent decline in glomerular filtration rate. Arch Intern Med 2006;166(8):846-852

35 Kang YY, Li Y, Wang JG. Ambulatory blood pressure monitoring in the prediction and prevention of coronary heart disease. Curr Hypertens Rep 2013;15(3):167-174

36 Zain-El MH, Snincak M, Pahuli K, Solarova Z, Hrabcakova P. Non-dipping morning blood pressure and isolated systolic hypertension in elderly. Bratisl Lek Listy (Tlacene Vyd) 2013;114(3):150-154

37 Cha RH, Kim S, Ae Yoon S, et al. Association between blood pressure and target organ damage in patients with chronic kidney disease and hypertension: results of the APrODiTe study. Hypertens Res 2014;37(2):172-178

38 Karakas MF, Buyukkaya E, Kurt M, et al. Assessment of left ventricular dyssynchrony in dipper and non-dipper hypertension. Blood Press 2013;22(3):144-150

39 Sherwood A, Bower JK, Routledge FS, et al. Nighttime blood pressure dipping in postmenopausal women with coronary heart disease. Am J Hypertens 2012;25(10):1077-1082

40 Cicek Y, Durakoglugil ME, Kocaman SA, et al. Non-dipping pattern in untreated hypertensive patients is related to increased pulse wave velocity independent of raised nocturnal blood pressure. Blood Press 2013;22(1):34-38

41 Witteman JC, Grobbee DE, Valkenburg HA, et al. J-shaped relation between change in diastolic blood pressure and progression of aortic atherosclerosis. Lancet 1994;343(8896): 504-507

42 Mitchell GF, Moyé LA, Braunwald E, et al. Sphygmomanometrically determined pulse pressure is a powerful independent predictor of recurrent events after myocardial infarction in patients with impaired left ventricular function. SAVE investigators. Survival and ventricular enlargement. Circulation 1997;96(12):4254-4260 